\title{
Characteristics of patients with antiphospholipid syndrome with major bleeding after oral anticoagulant treatment
}

\author{
G Castellino, M J Cuadrado, T Godfrey, M A Khamashta, G R V Hughes
}

\begin{abstract}
Objective-To study the demographic and clinical characteristics of patients with antiphospholipid syndrome (APS) with serious haemorrhagic complications of anticoagulant treatment in an attempt to establish risk factors for bleeding.

Methods-Patients with APS who were attending our lupus unit and who presented with severe bleeding while receiving oral anticoagulation were studied retrospectively. Severe bleeding was defined by the need for admission to hospital. Demographic data, clinical features, concomitant diseases and drugs, warfarin doses, duration of anticoagulation, and International Normalised Ratios (INR) at the time of bleeding were collected.

Results-Fifteen patients were included in the study (12 with systemic lupus erythematosus (SLE) plus APS and 3 with primary APS). The median age was 41.7 (range 27-66) and the median duration of the disease was 12.9 years (range 3-22). Duration of anticoagulation was between 10 days and 17 years. The INR at the time of bleeding was under 3 in 4 patients, between 3 and 4 in 5 patients and above 4 in 6 patients. There were 4 episodes of subdural haematoma, 4 episodes of renal haematoma (two after renal biopsy), 2 episodes of ovarian haemorrhage, 2 episodes of rectal haemorrhage, 1 episode of menorrhagia, 1 episode of haemarthrosis, and 1 episode of spinal haematoma. Concomitant drugs were aspirin in 9 patients, antibiotics in 2 patients, and azathioprine in 3 patients. In 6 patients hypertension was present as a concomitant disease. There were no deaths due to bleeding. Anticoagulant treatment was restarted in all patients and 3 of them had a new episode of bleeding.
\end{abstract}

Conclusion-No relation was established between age, duration of oral anticoagulant treatment, and bleeding. Concomitant drugs, mainly aspirin, and high blood pressure were present at the time of bleeding in a large number of patients. (Ann Rheum Dis 2001;60:527-530)

Antiphospholipid syndrome (APS) is one of the major causes of acquired thrombophilia, in which venous or arterial thrombosis, or both, may occur. It was originally recognised in patients with systemic lupus erythematosus (SLE), and soon after in patients without an underlying disease, the so called "primary antiphospholipid syndrome". The serological markers of the syndrome are antiphospholipid antibodies (aPL) directed against phospholipids and phospholipid-binding proteins.

Preventing thrombosis is one of the major aims in the treatment of APS. There is still no consensus about the duration and intensity of prophylactic antithrombotic treatment. The available studies suggest that oral anticoagulation should be maintained in the long term and the International Normalised Ratios (INR) should be around 3 in patients with aPL who have experienced previous thrombotic events. ${ }^{1}$ Clearly, aggressive anticoagulation carries with it a higher risk of bleeding.

In this survey, we have attempted to identify the risk factors for bleeding in 15 patients with serious haemorrhagic complications given oral anticoagulant treatment for primary or secondary APS.

\section{Patients and methods}

Fifteen patients attending the lupus clinic at St Thomas's Hospital and receiving oral anticoagulation for primary or secondary APS were admitted to hospital for severe bleeding between November 1989 and June 1999.

The study population included two women and one man with primary APS and 11 woman and one man with secondary APS. All the patients met the classification criteria for APS. ${ }^{2}$ Patients were included in this study if they had had a severe bleed requiring admission to hospital.

The presence or absence of lupus anticoagulant (LA) was confirmed by the method of Exner et al until July 1992 and after that by the dilute Russell's Viper Venom Time. Anticardiolipin antibodies (aCL) IgG and IgM isotypes were measured in all patients by standardised enzyme linked immunosorbent assay (ELISA). The results were expressed as IgG and IgM phospholipid units. They were reported as negative ( $<5$ units), low positive (5-20 units), medium (>20-60 units), or high (>60 units). Prothrombin time tests to monitor warfarin treatment were performed with various thromboplastins and the results were expressed as an INR.

Only patients with objectively verified haemorrhagic events (confirmed by an ultrasound, a computed tomography scan or by magnetic resonance imaging) were included in this study.

Table 1 gives demographic and clinical details of the 15 patients who were included in this study. 
Table 1 Patient (Pt) characteristics

\begin{tabular}{|c|c|c|c|c|c|c|c|c|c|c|}
\hline$P t$ & Age (yrs) & Race & $\operatorname{Sex}$ & $\begin{array}{l}\text { Diagnosis } \\
\text { (PAPS or } \\
\text { SAPS) * }\end{array}$ & $\begin{array}{l}\text { Disease } \\
\text { duration } \\
\text { (yrs) }\end{array}$ & $\begin{array}{l}\text { Venous } \\
\text { thrombotic } \\
\text { events }\end{array}$ & $\begin{array}{l}\text { Arterial } \\
\text { thrombotic } \\
\text { events }\end{array}$ & $\begin{array}{l}\operatorname{IgG} a C L^{\star} \\
\text { titre }\end{array}$ & $\begin{array}{l}\operatorname{IgM} a C L \\
\text { titre }\end{array}$ & $L A^{\star}$ \\
\hline 1 & 29 & White & Female & PAPS & 16 & 1 & 0 & Medium & Low & Yes \\
\hline 2 & 38 & Oriental & Female & SAPS & 17 & 0 & 2 & Medium & Negative & No \\
\hline 3 & 39 & White & Female & SAPS & 19 & 4 & 0 & Medium & Negative & No \\
\hline 4 & 38 & White & Female & SAPS & 22 & 0 & 1 & Low & Negative & Yes \\
\hline 5 & 53 & White & Female & PAPS & 11 & 0 & 1 & High & Negative & Yes \\
\hline 6 & 27 & White & Male & SAPS & 11 & 2 & 0 & High & High & Yes \\
\hline 7 & 46 & White & Female & SAPS & 15 & 3 & 0 & Negative & Negative & Yes \\
\hline 8 & 55 & Black & Female & SAPS & 13 & 1 & 1 & Medium & Negative & Yes \\
\hline 9 & 36 & White & Female & SAPS & 3 & 0 & 1 & Negative & Medium & No \\
\hline 10 & 53 & White & Female & SAPS & 10 & 2 & 0 & Low & Negative & No \\
\hline 11 & 35 & White & Male & PAPS & 12 & 5 & 0 & High & Negative & Yes \\
\hline 12 & 50 & White & Female & SAPS & 16 & 0 & 1 & High & High & Yes \\
\hline 13 & 32 & Black & Female & SAPS & 6 & 0 & 1 & Low & Negative & No \\
\hline 14 & 66 & White & Female & SAPS & 20 & 0 & 1 & Medium & Negative & Yes \\
\hline 15 & 29 & White & Female & SAPS & 3 & 1 & 1 & Low & Negative & Yes \\
\hline
\end{tabular}

^PAPS = primary antiphospholipid syndrome; SAPS = secondary antiphospholipid syndrome; $\mathrm{aCL}=$ anticardiolipin antibody LA= lupus anticoagulant.

\section{Results}

The median age of the patients was 41.7 (range 27-66) and the median duration of the disease was 12.9 years (range 3-22). Prior thrombotic events were venous in six patients, arterial in seven patients and both arterial and venous in two patients. Five patients were positive only for aCL (IgG or IgM), nine patients were positive for aCL and LA, and one patient was positive only for LA.

All patients had been taking a stable dose of warfarin with a median of $6.6 \mathrm{mg} /$ daily (range 2-13) for a median period of 39 months (range 0.3-204) before the haemorrhagic complication occurred. The INR at the time of the bleeding episode was $<3$ in four patients, between 3 and 4 in five patients and $>4$ in six patients. In only one patient was the platelet count lower than $150 \times 10^{9} / 1$.

Table 2 shows the characteristics of the haemorrhagic complications which occurred in the 15 patients.

The bleeding complications were subdural haematoma in four patients, renal haematoma in four patients (two after renal biopsy), ovarian haemorrhage in two patients, rectal haemorrhage in two patients, menorrhagia in one patient, haemarthrosis in one patient and spinal haematoma in one patient. All patients, after the haemorrhagic event, restarted warfarin and three of them had further haemorrhagic complications (one rectal bleeding, one menorrhagia, and one haemarthrosis). Aspirin was a concomitant drug in nine patients, antibiotics in two patients with intercurrent infection while three patients received immunosuppressive drugs for the underlying active disease. Hypertension was the most frequent concomitant disease, being present in six patients.

\section{Discussion}

Patients with APS have a strong tendency towards recurrent venous and arterial thrombosis and it is normal practice to give patients with a positive aCL or LA test, who have experienced previous thrombotic events, long term prophylactic anticoagulant treatment. Retrospective studies showed that treatment with warfarin was highly effective in preventing recurrent thrombosis, whereas aspirin was not. ${ }^{1}$

Table 2 Haemorrhagic complications

\begin{tabular}{|c|c|c|c|c|c|c|c|c|c|}
\hline$P t$ & Bleeding complication & $\begin{array}{l}\text { Duration of } \\
\text { warfarin before } \\
\text { bleeding } \\
\text { (months) }\end{array}$ & $\begin{array}{l}\text { Warfarin dose } \\
\text { (mg/day) }\end{array}$ & $\begin{array}{l}\text { INR } R^{\star} \text { at } \\
\text { bleeding }\end{array}$ & $\begin{array}{l}\text { Platelet } \\
<150 \times 10^{9} / l\end{array}$ & Aspirin & Other drugs & Hypertension & $\begin{array}{l}\text { Bleeding after } \\
\text { warfarin restarted }\end{array}$ \\
\hline 1 & $\begin{array}{l}\text { Ovarian haemorrhage } \\
\text { requiring oophorectomy }\end{array}$ & 3 & 2 & 2.8 & No & No & $\begin{array}{l}\text { Omeprazol } \\
\text { Ketoprofen }\end{array}$ & No & No \\
\hline 2 & Haemorrhagic ovarian cysts & 18 & 6 & 2.09 & No & Yes & $\begin{array}{l}\text { Steroid } \\
\text { Naproxen } \\
\text { Azathioprine }\end{array}$ & Yes & No \\
\hline 3 & Subdural haematoma & 204 & 8 & 5 & No & Yes & Ketoprofen & No & No \\
\hline 4 & Subdural haematoma & 11 & 10 & 3.5 & No & Yes & Atenolol & Yes & Yes, rectal bleeding \\
\hline 5 & Pericapsular renal bleeding & 20 & 7.5 & 6.4 & No & Yes & No & No & Yes, menorrhagia \\
\hline 6 & $\begin{array}{l}\text { Perinephric haematoma } \\
\text { (after renal biopsy) }\end{array}$ & 0.3 & 5 & 1.9 & Yes & No & $\begin{array}{l}\text { Amlodipine } \\
\text { Ranitidine }\end{array}$ & Yes & No \\
\hline 7 & Pericapsular renal bleeding & 6 & 5 & 10.4 & No & No & Hydroxychloroquine & No & Yes, haemarthrosis \\
\hline 8 & Subdural haematoma & 36 & 6 & 5.5 & No & Yes & $\begin{array}{l}\text { Steroids } \\
\text { Azathioprine } \\
\text { Antibiotics }\end{array}$ & Yes & No \\
\hline 9 & Subdural haematoma & 18 & 6 & 3.4 & No & No & No & No & No \\
\hline 10 & $\begin{array}{l}\text { Perinephric haematoma } \\
\text { (after renal biopsy) }\end{array}$ & 108 & 3 & 1.4 & No & Yes & $\begin{array}{l}\text { Verapamil } \\
\text { Heparin }\end{array}$ & Yes & No \\
\hline 11 & Intestinal haemorrhage & 18 & 10 & 3.8 & No & No & Antibiotics & No & No \\
\hline 12 & Menorrhagia & 72 & 6 & 3.5 & No & Yes & No & No & No \\
\hline 13 & Haemarthrosis & 60 & 13 & 18 & No & No & $\begin{array}{l}\text { Steroids } \\
\text { Azathioprine } \\
\text { Cyclosporin } \\
\text { Ranitidine }\end{array}$ & No & No \\
\hline 14 & Intestinal haemorrhage & 9 & 7.5 & 5 & No & Yes & Hydroxychloroquine & Yes & No \\
\hline 15 & Spinal haematoma & 2 & 10 & 3.8 & No & Yes & No & No & No \\
\hline
\end{tabular}

${ }^{\star} \mathrm{INR}=$ International Normalised Ratio. 
The high rate of recurrence suggests that patients with this syndrome require long term warfarin treatment. In our series high intensity anticoagulation (INR >3) was associated with $90 \%$ probability of a five year thrombosis-free follow up. ${ }^{1}$ Nevertheless, the benefits of long term anticoagulation should be balanced against the risks of bleeding.

In this report we described 15 patients with serious haemorrhagic complications of oral anticoagulation with primary or secondary APS admitted to St Thomas's Hospital between November 1989 and June 1999. All our patients had previously experienced a thrombotic event and had a positive test for LA, aCL or both.

Hart et al suggested that intracranial haemorrhage is the most common, feared, and frequently lethal complication of oral anticoagulant treatment. ${ }^{3}$ In our series subdural haematoma was the most common localisation of bleeding (four patients). Renal haematoma was present in four patients and in two of them this complication followed a surgical procedure (renal biopsy). In both patients, warfarin had been switched to heparin 48 hours before renal biopsy. Perinephric haematoma developed two days after the renal biopsy in one patient while receiving heparin, and nine days later in the other who had restarted warfarin. Interestingly, both of them had high blood pressure, with mild thrombocytopenia in one (platelet count $\left.97 \times 10^{9} / 1\right)$.

Age (older than 65) has been identified as a risk factor for bleeding in patients with $\mathrm{APS}^{4}$ and other diseases. ${ }^{5}$ Our study group was much younger with a median age of 41 and only one patient was older than 65 . Therefore, our results have to be interpreted with caution and might not be applicable to an older population.

Fihn suggested that the risk of major bleeding in patients receiving oral anticoagulant treatment is cumulative with more than $20 \%$ of patients experiencing major bleeding episodes within the first four years of treatment. ${ }^{6}$ In our series the range of anticoagulation time was very wide (10 days-17 years), with 11 of 15 patients bleeding in the first 48 months.

Uncontrolled hypertension is a risk factor for bleeding in patients receiving warfarin treatment. ${ }^{5-7}$ We found that six of our patients had hypertension at the time of bleeding and four of them bled with an INR under 4 .

Other drugs can interfere with oral anticoagulant treatment. The combination of warfarin and aspirin increases the risk of bleeding. ${ }^{8}$ Nine patients were receiving aspirin as concomitant drugs and five of them bled with an INR lower than 3 or between 3 and 4 . Five other patients had both aspirin and hypertension as additional risk factors for their haemorrhage. Two patients bled while receiving antibiotics for an intercurrent infection. An important interaction has been noted between azathioprine and warfarin: when azathioprine is reduced or discontinued, the INR may increase with the potential for bleeding. ${ }^{9}$ This was so for two of our patients who bled after a reduction of azathioprine dosage. More recently, an interaction between high dose intravenous methylprednisolone and warfarin with a frank increase in the INR has been described. Concomitant administration of oral anticoagulants and methylprednisolone made oral anticoagulation potentially fatal. ${ }^{10}$ We were not aware of this potential interaction and this factor was not documented in our patients.

An INR >3 has been recommended in patients with APS to prevent recurrent thrombosis. ${ }^{1}$ However, it has been reported that each increase of 1 in the INR is associated with a $42 \%$ increase in major bleeding episodes ${ }^{11}$ and that the risk of intracranial haemorrhage markedly increases with an INR between 3.7 and 4.0. ${ }^{12}$ In our series four patients bled with an INR lower than 3. Three of these four patients had high blood pressure at the time of bleeding. Two of them were receiving aspirin and warfarin. In one patient with an INR of 2.8 we did not find any other risk factors associated with bleeding. Recently, it has been reported that the cytochrome P450 CYP2C9 is responsible for the metabolism of warfarin and that two allelic variants of this enzyme, differing by a single amino acid substitution, are associated with impaired hydroxylation of warfarin. The CYP2C9 polymorphism might identify a subgroup of patients who are at higher risk of bleeding complications. ${ }^{13}$

In none of our patients was the bleed fatal and only three had further haemorrhagic complications after warfarin was resumed. Two patients had minor bleeding and one had haemarthrosis. The rate of life threatening bleeding in subjects taking warfarin, based on a prospective study is at least $0.25 \%$ a year. ${ }^{14}$ In APS, serious bleeding complications may occur, but their risk is not higher than that found in other thrombotic conditions warranting oral anticoagulation. ${ }^{15}$ Our own study ${ }^{1}$ showed that the risk of recurrent thrombosis is higher than the risk of bleeding.

In summary, long term, high intensity oral anticoagulation is still the best treatment to prevent further thrombotic events in patients with APS. Caution is warranted in patients with uncontrolled blood pressure. Aspirin as concomitant treatment with warfarin should be used only in selected cases.

This work was supported by Lupus UK.

1 Khamashta MA, Cuadrado MJ, Mujic F, Taub NA, Hunt BJ, Hughes GR. The management of thrombosis in the antiphospholipid antibody syndrome. $N$ Engl J Med 1995:332:993-7.

2 Harris EN, Baguley E, Asherson RA, Hughes GRV. Clinical and serological features of the antiphospholipid syndrome (APS) [abstract]. Br J Rheumatol 1987;26(suppl 2):19.

3 Hart RG, Boop BS, Anderson DC. Oral anticoagulants and intracranial hemorrhage. Facts and hypotheses. Stroke 1995;26:1471-7.

4 Piette JC, Cacoub P. Antiphospholipid syndrome in the elderly: caution. Circulation 1998;97:2195-6.

5 Landefeld CS, Goldman L. Major bleeding in outpatients treated with warfarin: incidence and prediction by factors known at the start of outpatient therapy. Am J Med 1989; $87: 144-52$.

6 Fihn SD. Risk factors for complications of chronic anticoagulation. Ann Intern Med 1993;118:511-20.

7 The Medical Research Council's General Practice Research Framework. Thrombosis prevention trial: randomised trial of low intensity oral anticoagulation with warfarin and low dose aspirin in the primary prevention of ischaemic heart disease in men at increased risk. Lancet 1998; 351:233-41. 
8 Gullov AL, Koefoed BG, Peterson P. Bleeding during warfarin and aspirin therapy in patients with atrial fibrillation: the AFASAK 2 study. Atrial fibrillation aspirin and anticoagulation. Arch Intern Med 1999;159:1322-8.

9 Rivier G, Khamashta MA, Hughes GRV. Warfarin and azathioprine: a drug interaction does exist. Am J Med 1993;95:342.

10 Costedoat-Chalumeau N, Amoura Z, Aymard G, Sevin O, Wechsler B, Cacoub P, et al. Potentiation of vitamin K antagonists by high dose intravenous methylprednisolone. Ann Intern Med 2000;132:631-5.

11 van der Meer FJM, Rosendaal FR, Vandenbroucke JP, Briet E. Bleeding complications in oral anticoagulant patients. Arch Intern Med 1993;153:1557-62.
12 Hylek EM, Singer DE. Risk factors for intracranial hemorrhage in outpatients taking warfarin. Ann Intern Med rhage in outpatient

13 Aithal GP, Day CP, Kesteven PJ, Daly AK. Association of polymorphisms in the cytochrome P450 CYP2C9 with warfarin dose requirement and risk of bleeding complications. Lancet 1999;353:717-19.

14 Palareti G, Leali N, Cocheri S, Poggi M, Manotti C, D'Angelo A, et al. Bleeding complications of oral anticoagulant therapy. Lancet 1996;348:423-8.

15 Al-Sayegh FA, Ensworth S, Huang S, Stein H, Kinkhoff AV. Hemorrhagic complications of long-term anticoagulant therapy in 7 patients with SLE and antiphospholipid syndrome. J Rheumatol 1997;24:1716-18.

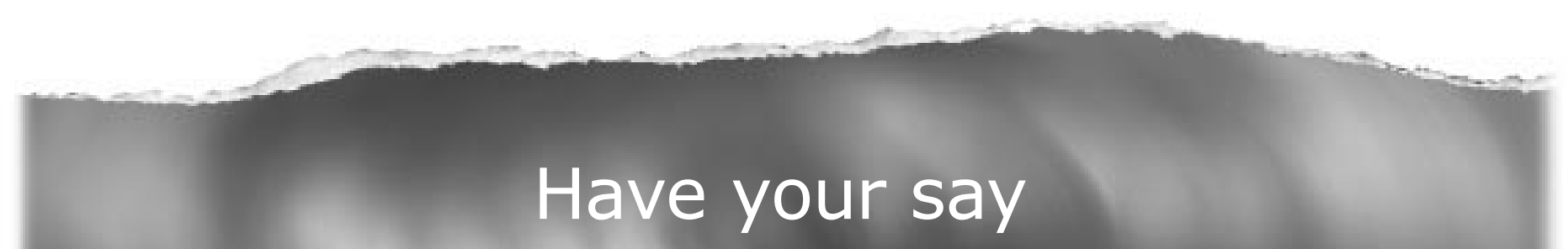

\section{eLetters}

If you wish to comment on any article published in Annals of the Rheumatic Diseases you can send an eLetter using the eLetters link at the beginning of each article. Your response will be posted on Annals of the Rheumatic Diseases online within a few days of receipt (subject to editorial screening).

www.annrheumdis.com 